Purdue University Purdue e-Pubs

$1-31-2007$

\title{
Characteristics of an Evaporating Thin Film in a Microchannel
}

Hao Wang

S V. Garimella

Purdue University, sureshg@purdue.edu

Jayathy Y. Murthy

Follow this and additional works at: http:/ / docs.lib.purdue.edu/coolingpubs

Wang, Hao; Garimella, S V.; and Murthy, Jayathy Y., "Characteristics of an Evaporating Thin Film in a Microchannel" (2007). CTRC Research Publications. Paper 14.

http://dx.doi.org/10.1016/j.ijheatmasstransfer.2007.01.052

This document has been made available through Purdue e-Pubs, a service of the Purdue University Libraries. Please contact epubs@purdue.edu for additional information. 


\title{
Characteristics of an Evaporating Thin Film in a Microchannel ${ }^{\S}$
}

\author{
Hao Wang, Suresh V. Garimella ${ }^{\mathbb{T l}}$ and Jayathi Y. Murthy \\ Cooling Technologies Research Center, School of Mechanical Engineering, \\ Purdue University, West Lafayette, Indiana 47907-2088 USA
}

\begin{abstract}
An evaporating meniscus in a microchannel is investigated through an augmented Young-Laplace model and the kinetic theory-based expression for mass transport across a liquid-vapor interface. The complete expression for mass transport is employed without any approximations and boundary conditions for the film profile are developed. The thin-film and the intrinsic-meniscus regions are distinguished based on the disjoining pressure variation along the meniscus. While heat transfer in the thin-film region is found to be relatively insensitive to channels larger than a few micrometers in radius, that in the intrinsic meniscus is quite sensitive to channel size. The role of evaporation suppression due to capillary pressure in both regions is discussed. Compared to the relatively small contribution to overall heat transfer from the thin-film region, the micro region (defined here as extending from the non-evaporating region to a location where the film is $1 \mu \mathrm{m}$ thick) is found to account for more than $50 \%$ of the total heat transfer.
\end{abstract}

Keywords: Meniscus, thin film, triple line, microchannel, evaporation, liquid cooling

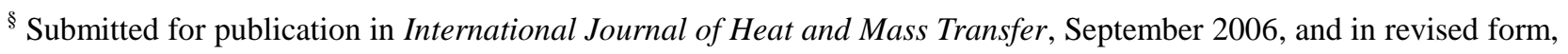
January 2007

II Author to whom correspondence should be addressed: 765-494-5621, sureshg@ purdue.edu
} 


\section{NOMENCLATURE}

\begin{tabular}{|c|c|c|c|}
\hline$A$ & dispersion constant $(\mathrm{J})$ & $y$ & $y$ coordinate $(\mathrm{m})$ \\
\hline$H$ & height of channel (m) & \multicolumn{2}{|c|}{ Greek symbols } \\
\hline$h_{f g}$ & latent heat of evaporation $(\mathrm{J} / \mathrm{kg})$ & $\delta$ & liquid layer thickness $(\mathrm{m})$ \\
\hline$k_{l}$ & liquid conductivity (W/mK) & $\delta_{0}$ & non-evaporating layer thickness (m) \\
\hline$m^{\prime}$ & mass flow rate $(\mathrm{kg} / \mathrm{ms})$ & $v$ & kinematic viscosity $\left(\mathrm{m}^{2} / \mathrm{s}\right)$ \\
\hline$m^{\prime \prime}$ & interface net mass flux $\left(\mathrm{kg} / \mathrm{m}^{2} \mathrm{~s}\right)$ & $\mu$ & dynamic viscosity $\left(\mathrm{Ns} / \mathrm{m}^{2}\right)$ \\
\hline $\bar{M}$ & molecular weight $(\mathrm{kg} / \mathrm{mol})$ & $\rho_{l}$ & liquid density $\left(\mathrm{kg} / \mathrm{m}^{3}\right)$ \\
\hline $\bar{R}$ & universal gas constant $(\mathrm{J} / \mathrm{mol} \mathrm{K})$ & $\rho_{v}$ & vapor density $\left(\mathrm{kg} / \mathrm{m}^{3}\right)$ \\
\hline$P_{d}$ & disjoining pressure $\left(\mathrm{N} / \mathrm{m}^{2}\right)$ & $\sigma$ & surface tension coefficient $(\mathrm{N} / \mathrm{m})$ \\
\hline$P_{l}$ & liquid pressure $\left(\mathrm{N} / \mathrm{m}^{2}\right)$ & $\hat{\sigma}$ & accommodation coefficient \\
\hline$\Delta P_{l}$ & change of liquid pressure $\left(\mathrm{N} / \mathrm{m}^{2}\right)$ & \multicolumn{2}{|c|}{ Subscripts } \\
\hline$P_{\text {sat }}$ & saturation pressure $\left(\mathrm{N} / \mathrm{m}^{2}\right)$ & $c$ & condensation \\
\hline$P_{v}$ & vapor pressure $\left(\mathrm{N} / \mathrm{m}^{2}\right)$ & $e$ & evaporation \\
\hline$P_{v_{-} e q u}$ & equilibrium pressure $\left(\mathrm{N} / \mathrm{m}^{2}\right)$ & $l$ & liquid \\
\hline$q$ & integrated heat transfer rate $(\mathrm{W} / \mathrm{m})$ & $l v$ & liquid-vapor interface \\
\hline$R$ & meniscus radius (m) & sat & saturated \\
\hline$R^{*}$ & $\begin{array}{l}\text { asymptotic intrinsic meniscus } \\
\text { radius }(\mathrm{m})\end{array}$ & sum & sum \\
\hline$T$ & temperature $(\mathrm{K})$ & $t$ & thin film region \\
\hline$u$ & velocity along $x$ axis $(\mathrm{m} / \mathrm{s})$ & $v$ & vapor \\
\hline$V$ & molar volume $\left(\mathrm{m}^{3} / \mathrm{mol}\right)$ & ref & reference state \\
\hline$x$ & $x$ coordinate $(\mathrm{m})$ & & \\
\hline
\end{tabular}

\section{INTRODUCTION}

When a liquid wets a solid wall, the extended meniscus can typically be divided into three regions as illustrated in Fig. 1: an adsorbed or non-evaporating region where liquid is adsorbed on the wall; a thin-film or transition region where effects of long-range molecular forces (disjoining pressure) are felt; and an intrinsic meniscus region where capillary forces dominate. Of these, the thin-film region is characterized by high heat transfer rates because of the very low thermal resistance across the liquid film. Porous or grooved surfaces can help to create thin films for enhanced operation of heat transport devices such as heat pipes and capillary pumped loops.

Deryagin et al. [1,2] demonstrated liquid pressure reduction in the thin-film region due to disjoining pressure. Potash and Wayner [3] concluded that the variation of disjoining pressure and capillary pressure along the meniscus provides the necessary pressure gradient for liquid supply into the thin-film region. 
Wayner et al. [4] discussed the effects of disjoining pressure on liquid supply as well as its role in suppressing evaporation. An augmented Young-Laplace equation was obtained for force balance on the thin film by introducing a disjoining pressure such that $P_{v}=P_{l}+P_{c}+P_{d}$. Schonberg et al. [5] investigated the thin film by ignoring $P_{c}$. Hallinan et al. [6] and DasGupta et al. [7] developed a fourth-order ordinary differential equation for solving the augmented Young-Laplace equation and obtained the thickness profile of the extended meniscus. The influence of superheat on the thin film profile was discussed. Park et al. [8] proposed a mathematical model which included the vapor region and a slip boundary condition. It was concluded that the pressure gradient in the vapor region significantly affected the thin-film profile. Wee [9] discussed the effects of liquid polarity, slip boundary and thermocapillary effects on the thin-film profile. The polarity effect was found to elongate the transition region while suppressing evaporation. Recently, binary liquids [10] have been found to induce a distillation-driven capillary stress to counteract the thermocapillary stress, leading to an elongation in thin-film length. Atomistic simulations by Freund [11] showed that the thermal resistance at the solid-liquid interface is significant in very thin films. A Kapitza resistance was employed to obtain the solid-liquid interface temperature.

The menisci in more complex geometries have also been studied. Stephan and Busse [12] calculated the heat and mass transfer in the micro-region and then combined the solution with the macroscopic meniscus within open grooves. $\quad \mathrm{Xu}$ and Carey [13] conducted a combined analytical and experimental investigation on the liquid flow in $\mathrm{V}$ grooves and emphasized the importance of disjoining pressure on the overall heat transfer. Ma and Peterson [14] proposed a mathematical model for the evaporation heat transfer coefficient and temperature variation along the axial direction of a groove, which led to a better understanding of the axial heat transfer coefficient and temperature distribution on grooved surfaces. Morris [15] suggested a universal relationship between heat flow, contact angle, interface curvature, superheat and material properties, which can be extended to different geometries. Recently, thin film evaporation in a microchannel was studied [16]. The thin film was maintained throughout at a temperature below the saturation temperature corresponding to the imposed pressure, and the gas domain was assumed to consist of a mixture of air and vapor. The vapor diffusion in the gas domain was calculated to obtain evaporation flux, and heat transfer results in the form of a local Nusselt number were reported.

In the present work, an evaporating meniscus in a channel is investigated. The meniscus is superheated, and vapor space is assumed to consist of pure saturated vapor. The present model complements previous studies [3-16] in three ways. First, heat transfer in the thin-film and micro regions is quantitatively compared and the relative contributions of the two regions to the overall heat transfer delineated. Second, the kinetic theory-based expression for mass transport across a liquid-vapor interface [17] is used instead of a simplified version often adopted in prior studies (which assume $T_{l v} \approx T_{\text {sat }}$ ); the simplified expression is shown 
in this work to underpredict the total heat transfer at high superheats. Third, the influence of capillary suppression and channel size on heat transfer from the thin-film region is discussed in detail.

\section{THEORETICAL MODEL}

\subsection{Thin-Film Profile}

The equations governing the thin-film profile have been extensively discussed in the literature [3-9] and are briefly reviewed here. The pressure difference between vapor and liquid at the liquid-vapor interface is due both to the capillary and disjoining pressures, and is expressed using the augmented Young-Laplace equation [4]:

$$
P_{v}=P_{l}+P_{c}+P_{d}
$$

The disjoining pressure for a non-polar liquid is expressed as $[4,18]$

$$
P_{d}=A / \delta^{3}
$$

where $A$ is the dispersion constant and $\delta$ the film thickness. The capillary pressure is the product of interfacial curvature $K$ and surface tension coefficient $\sigma$

$$
P_{c}=\sigma K, \quad K=\delta^{\prime \prime}\left(1+\delta^{2}\right)^{-1}
$$

where $\delta^{\prime}$ and $\delta^{\prime \prime}$ are respectively the first and second derivatives of thickness with respect to length $x$. The model is often simplified in the literature by assuming a value of zero for $\delta^{\prime}$ [6-9]. This term is retained in the present work to better model the beginning of the intrinsic meniscus where the slope may not be negligible. The problem under consideration is illustrated in Fig. 1.

Combining Eqs. (1)-(3) and differentiating with respect to $x$, the following third-order differential equation is obtained for the thin-film profile $\delta(x)$

$$
\delta^{\prime \prime \prime}-\frac{3 \delta^{\prime} \delta^{\prime \prime 2}}{1+\delta^{\prime 2}}+\frac{1}{\sigma}\left(\frac{d P_{l}}{d x}-\frac{3 A}{\delta^{4}} \delta^{\prime}\right)\left(1+\delta^{\prime 2}\right)^{1.5}=0
$$

assuming uniform $P_{v}$ along the meniscus. In view of the very low Reynolds number and the large length-toheight ratio of the thin film, lubrication theory is employed to obtain the pressure gradient in Eq. (4). A noslip boundary condition at the wall and a no-shear boundary condition at the liquid-vapor interface are imposed. Under these assumptions, the liquid pressure gradient $\mathrm{d} p_{l} / \mathrm{d} x$ may be related to the mass flow rate $m^{\prime}(x)$. At steady state, the mass flow rate $m^{\prime}(x)$ at a position $x$ is equal to the integral of the net evaporative mass flux from the beginning of the film to the local position. The liquid pressure gradient may then be obtained as 


$$
\frac{d P_{l}}{d x}=\frac{3 v}{\delta^{3}} \int_{-\infty}^{x} m^{\prime \prime} d x
$$

Substituting the pressure gradient into Eq. (4) and further differentiating with respect to $x$, a fourth-order ordinary differential equation is obtained for the thin-film profile:

$$
\frac{d}{d x}\left(\left[\frac{\sigma \delta^{\prime \prime \prime}}{\left(1+\delta^{\prime 2}\right)^{1.5}}-\frac{3 \sigma \delta^{\prime} \delta^{\prime \prime 2}}{\left(1+\delta^{\prime 2}\right)^{2.5}}-\frac{3 A \delta^{\prime}}{\delta^{4}}\right] \frac{\delta^{3}}{3 v}\right)=-m^{\prime \prime}
$$

The local evaporation mass flux $m^{\prime \prime}$ is determined from the interfacial mass transport as discussed below.

\section{$\underline{2.2 \text { Interfacial Mass Transport }}$}

As reviewed in [19], Schrage [17] proposed a theory for evaporation at an interface, in which the net mass flux across the interface $m^{\prime \prime}$ is the difference between the fluxes of pure condensation $m^{\prime \prime}{ }_{c}$ and pure evaporation $m^{\prime \prime}$, i.e., $m^{\prime \prime}=m^{\prime \prime}{ }_{e}-m^{\prime \prime}$. Assuming the evaporation coefficient and the condensation coefficient to be equal to each other for simplicity as suggested in the reviews in $[19,28]$, the net mass flux may finally be written in the form that is employed in the present thin-film model:

$$
m^{\prime \prime}=\frac{2 \hat{\sigma}}{2-\hat{\sigma}}\left(\frac{\bar{M}}{2 \pi \bar{R}}\right)^{1 / 2}\left(\frac{P_{v_{-} e q u}\left(T_{l v}\right)}{T_{l v}^{1 / 2}}-\frac{P_{v}}{T_{v}^{1 / 2}}\right)
$$

The equilibrium vapor pressure $P_{v_{-} e q u}$ is the pressure at which the vapor is in equilibrium with the liquid. For a flat interface on a bulk liquid (no capillary or disjoining pressure), $P_{v_{-} e q u}$ is equal to the saturation pressure $P_{s a t}$ at $T_{l v}$ [20]. In a thin film, however, the disjoining pressure and capillary pressure affect the equilibrium state and $P_{v_{-} e q u}$ is not equal to $P_{\text {sat }}$, but is in fact smaller [21]:

$$
P_{v_{-} e q u}\left(T_{l v}\right)=P_{s a t}\left(T_{l v}\right) \exp \left[\frac{P_{v_{-} e q u}\left(T_{l v}\right)-P_{s a t}\left(T_{l v}\right)-\left(P_{d}+P_{c}\right)}{\rho_{l} T_{l v} \bar{R} / \bar{M}}\right]
$$

where

$$
P_{\text {sat }}\left(T_{l v}\right)=P_{\text {sat_ref }}\left(T_{\text {sat_ref }}\right) \exp \left[\frac{\bar{M} h_{f g}}{\bar{R}}\left(\frac{1}{T_{\text {sat_ref }}}-\frac{1}{T_{l v}}\right)\right]
$$

It is seen that the role of disjoining and capillary pressures is to reduce $P_{v_{-} e q u}\left(T_{l v}\right)$, and thus, to suppress evaporation. There is much debate about the value of the accommodation coefficient $[22,28]$, especially for polar liquids such as water and methanol. In experiments, non-polar liquids commonly have yielded higher accommodation coefficients than polar liquids. Non-polar liquids including carbon tetrachloride, benzene, and hexadecane have been experimentally found to have an accommodation coefficient of unity [22, 28]. In the present work, since octane is a non-polar liquid, we assume its accommodation coefficient to be unity. More accurate values would require more detailed experiments. 
In the development thus far, $T_{l v}$ is unknown. However, it is noted that the evaporation heat flux on the interface is equal to the conduction heat flux through the thin film:

$$
m^{\prime \prime} h_{f g}=\frac{k_{l}\left(T_{w}-T_{l v}\right)}{\delta}
$$

By solving Eqs. (7)-(9) together, $T_{l v}, P_{\text {sat }}, P_{v_{-} e q u}$, and $m^{\prime \prime}$ are obtained; of these, the calculated $m^{\prime \prime}$ is used to compute the thin film profile via Eq. (6).

In much of the published literature [4-6,9-10] $\mathrm{m}^{\prime \prime}$ is calculated using the evaporation model proposed by Wayner et al. [4]:

where

$$
\begin{gathered}
m^{\prime \prime}=a\left(T_{l v}-T_{v}\right)-b\left(p_{d}+p_{c}\right) \\
a=C\left(\frac{\bar{M}}{2 \pi \bar{R} T_{l v}}\right)^{1 / 2} \frac{P_{v} \bar{M} h_{f g}}{\bar{R} T_{v} T_{l v}}, \quad b=C\left(\frac{\bar{M}}{2 \pi \bar{R} T_{l v}}\right)^{1 / 2} \frac{V_{l} P_{v}}{R T_{l v}}
\end{gathered}
$$

The second term on the right hand side of Eq. (10a) represents the suppression of the evaporation rate by disjoining and capillary pressures. It was simplified from Schrage's original expression, Eq. (7), by using an extended Clapeyron equation [4] and the approximations $T_{l v} \approx T_{v}$ and $P_{v_{-} e q u} \approx P_{v}$. A comparison of the evaporation heat transfer coefficient calculated from the original expression in Eq. (7) as $h_{l v}=m^{\prime \prime} h_{f g} /\left(T_{l v}-T_{v}\right)$ with that calculated from Wayner's Eq. (10) is shown in Fig. 2 for different superheats. It is seen that the two equations yield nearly identical results for superheats under $5 \mathrm{~K}$, but that Eq. (10) significantly underestimates $h_{l v}$ for large superheats. Superheats considered in the literature [4-6,9-10] have been generally lower than 1 $\mathrm{K}$, which has allowed use of the simplified form in Eq. (10). However, under high heat fluxes, such as in Schonberg et al. [23] who encountered a superheat of $5.2 \mathrm{~K}$, the simplified form would lead to an underestimation of $h_{l v}$. High superheats are also expected in the meniscus at the bottom of a bubble during boiling. In the present work, Schrage's original expression is employed to allow for the study of higher superheats. A detailed analysis of the impact of the use of Eq. (10) versus Eq. (7) in thin film calculation is presented in Section 3.3.

\subsection{Solution Method and Boundary Conditions}

The particular system considered is the evaporation of a film of octane on a silicon substrate. The vapor domain is assumed to be saturated at $T_{v}$ and $P_{v}$. The relevant properties are listed in Table 1. The dispersion constant $A$ is assumed to be $-3.18 \times 10^{-21} \mathrm{~J}$ based on the data in [24], which considered octane on silicon with air at room temperature. The accommodation coefficient $\hat{\sigma}$ for the evaporation calculation is assumed to be unity for octane, a non-polar liquid, as discussed earlier. These values, $A=-3.18 \times 10^{-21} \mathrm{~J}$ and $\hat{\sigma}=1$, were also used in [5]. 
Eq. (6) is a fourth-order, non-linear ODE and can be treated as an initial-value problem by specifying the conditions at the beginning of the thin-film region, $x=0$, where the non-evaporating film ends and the evaporating thin film starts, as shown in Fig. 1. Four initial conditions are needed, i.e., $\delta(x=0), \delta^{\prime}(0), \delta^{\prime \prime}(0)$, and $\delta^{\prime \prime \prime}(0)$. The method proposed by Dormand and Prince [25] is employed to solve this equation. The initial thickness $\delta(0)$ should be equal to the non-evaporating thickness $\delta_{0}$, which is obtained by setting the net mass flux to zero in Eq. (7). Setting $m^{\prime \prime}=0$ and $T_{l v}=T_{w}$ (interface temperature in the non-evaporating region is approximated to be the wall temperature [4,5]) in Eq. (7) gives $P_{v_{-} \text {equ }}$; substituting $P_{v_{-} \text {equ }}$ into Eq. 8, the sum of the disjoining and capillary pressures needed to completely suppress evaporation is obtained as:

$$
P_{d 0}+P_{c 0}=-\rho_{l} T_{w} \frac{\bar{R}}{\bar{M}} \ln \left(\sqrt{\frac{T_{w}}{T_{v}}} \frac{P_{v}}{P_{s a t}\left(T_{w}\right)}\right)+P_{v} \sqrt{\frac{T_{w}}{T_{v}}}-P_{s a t}\left(T_{w}\right)
$$

Assuming that the curvature of the non-evaporating region is zero, $P_{c 0}=0$. Then $P_{d 0}$ is obtained, from which the thickness of the non-evaporating region $\delta_{0}$ can be computed. For octane with $1 \mathrm{~K}$ superheat, values of $P_{d 0}$ $=6.3 \times 10^{5} \mathrm{~Pa}$ and $\delta_{0}=1.71 \mathrm{~nm}$ are obtained.

However, it is found that if $\delta_{0}$ is used as the thickness at $x=0$, the evaporation mass flux is zero along the entire (extended) meniscus for the following two reasons. (a) At $x=0, \int_{-\infty}^{x} m^{\prime \prime} d x=0$, so that $\left(d P_{l} / d x\right)=$ 0 according to Eq. (5). Furthermore, $d\left(P_{c}+P_{d}\right) / d x=0$. Since the suppression of evaporation is determined by $P_{c}+P_{d}$, this latter condition implies that this suppression effect does not change with film thickness, so that $d m^{\prime \prime} / d x=0$. (b) With $m^{\prime \prime}=0$ and $d m^{\prime \prime} / d x=0$ at $x=0, m^{\prime \prime}=0$ is found at the next step $x=0+d x$, which renders the accumulated mass flux $\int_{-\infty}^{x} m^{\prime \prime} d x$ to continue to be zero along $x$. Continuing this analysis, each successive step also has zero evaporative mass flux, so that the entire thin film would have no evaporation. Thus, a value slightly larger than $\delta_{0}$ is chosen as the condition at $x=0$. Since evaporation near the beginning of the thin-film region is negligible, this perturbation has an insignificant influence on the overall thin-film heat transfer. This is seen in the plot of cumulative heat transfer $q(x)$ up to location $x$ and capillary pressure $P_{c}$ for two different choices of $\delta(0), 1.8$ and $3.4 \mathrm{~nm}$, in Fig. 3. In the calculations presented in this paper, $\delta(0)$ $=3.4 \mathrm{~nm}$ is used.

In terms of the other three conditions at $x=0$, the initial slope for a completely wetting film is close to zero; in the present work, $\delta^{\prime}(0)=1 \times 10^{-11}$ is used. Further reducing the value to zero does not significantly change the resulting film profile. Since $\delta^{\prime \prime}(0)$ cannot be specified directly, a far-field boundary condition is used as in [6,23]. In [23], the far-field condition is set by assuming that the film slope approaches a constant value (i.e., the meniscus radius $R$ approaches infinity). For a meniscus in a channel, however, $R$ should approach the constant radius $R^{*}$ in the intrinsic meniscus, which is approximately half of the channel height $H$ when the liquid is completely wetting [26,27]. The variation of meniscus radius with respect to $x$ is discussed 
further in Section 3. Iterative calculations are employed to obtain $\delta^{\prime \prime}(0)$ for a specified $R^{*}$ by changing $\delta^{\prime \prime}(0)$ until the desired value of $R^{*}$ is obtained. The imposition of the far-field curvature $R^{*}$ is found to be critical. It is found that small changes in $\delta(0)$ or $\delta^{\prime}(0)$ make negligible difference to the thin film profile and heat transfer characteristics as long as $R^{*}$ is the same, as in the example shown in Fig. 3. The fourth condition,

$\delta^{\prime \prime \prime}(0)$, is obtained from Eq. (4) in terms of $\delta(0), \delta^{\prime}(0)$ and $\delta^{\prime \prime}(0)$, together with $\int_{-\infty}^{0} m^{\prime \prime} d x=0$. This fourth condition has a very weak influence on the thin film profile obtained.

\section{RESULTS AND DISCUSSION}

Characteristics of the thin-film region are presented in this section, based on the model developed above, which employs the evaporation model of Schrage [17]. The variations of different pressure components along the meniscus are analyzed to delineate their effect on evaporation in the thin-film region. The effects on evaporation of suppression due to capillary pressure, wall superheat and channel size are discussed.

\subsection{Thin-Film Characteristics}

The variation of disjoining pressure $\left(P_{d}\right)$, capillary pressure $\left(P_{c}\right)$, and liquid pressure change $\left(\Delta P_{l}=P_{l}-\right.$ $\left.P_{l}(x=0)\right)$ along the length of the liquid film are plotted in Fig. 4 for two different channel sizes, $R^{*}=2500 \mathrm{~nm}$ and $R^{*}=200 \mathrm{~nm}$. The sum of the three components of pressure $\left(P_{\text {sum }}=P_{d}+P_{c}+\Delta P_{l}\right)$ is always a constant along the film length, as expected from the Young-Laplace equation.

The evaporated liquid is replenished by the liquid pressure gradient. For the first $40 \mathrm{~nm}$ along the thinfilm region, Fig. 4(a) shows that the increase in liquid pressure is solely supported by the reduction in disjoining pressure. Beyond this length, the capillary pressure also decreases and begins to contribute to the increase in liquid pressure, which is consistent with the observations of [7]. In Fig. 4(b), it is seen that the capillary pressure is maintained at a high level and does not drop in the case of the much smaller channel size. The drop in capillary pressure is important for flattening the thickness profile and enhancing liquid pumping. It will be seen later (in Fig. 5) that the greater the drop in capillary pressure, the more flat is the thin film.

The thin-film region is generally understood to be dominated by disjoining pressure while the intrinsic meniscus is dominated by capillary pressure. The locations at which the disjoining pressure drops to $1 / 100^{\text {th }}$, $1 / 1000^{\text {th }}$, and $1 / 10,000^{\text {th }}$ of $P_{d 0}$ are marked in Fig. 4(a) and (b). It is seen that disjoining pressure ceases to contribute to $P_{1}$ once it drops to values in the range of $1 / 1000^{\text {th }}$ of $P_{d 0}$. In the present work, the thin-film region is identified as ending at a location when the disjoining pressure drops to $1 / 5000^{\text {th }}$ of $P_{d 0}$, beyond which the intrinsic meniscus region starts. For example, in Fig. 4(a), the end of the thin-film region is identified as being at $x=154 \mathrm{~nm}$, where $P_{d}=3.15 \times 10^{2} \mathrm{~Pa}$. At this location, $P_{d}$ is only $1 / 300^{\text {th }}$ of $P_{c}$ and its contribution to 
the increase in $P_{l}$ with increasing $x$ is negligible from this location onwards. Similar results are noted from Fig. 4(b) for a much smaller channel size.

\subsection{Intrinsic Meniscus Radius}

In Fig. 4 it is seen that $P_{c}(=\sigma / R)$ approaches a constant value in the intrinsic meniscus, indicating that the film radius approaches the value $R^{*}$, which is approximately half of the channel height $H$ when the liquid is completely wetting $[6,26,27]$. A larger $R^{*}$ corresponds to a flatter thickness profile so that the thin film region is larger, as is evident from a comparison of Fig. 4(a) and (b). The importance of $R^{*}$ is demonstrated by its effect on the thin-film profiles and cumulative heat transfer rate in Fig. 5(a) and (b). A larger $R^{*}$ corresponds to better thin film heat transfer, as seen in Fig. 5(b).

When the radius $R^{*}$ exceeds a certain value, however, the thin film thickness profile $\delta=\delta(x)$ reaches an invariant state: the profiles for $R^{*}=2500$ and $6.1 \times 10^{4} \mathrm{~nm}$ are seen in Fig. 5 (a) to be quite similar, and the corresponding heat transfer curves almost overlap each other in Fig. 5(b). As seen in Table 2(a), the thin film heat transfer $q_{t}$ does not change much with $R^{*}$ beyond $R^{*}>2500 \mathrm{~nm}$. The differences due to changes in $R^{*}$ are most evident in the intrinsic meniscus rather than in the thin-film region.

\subsection{Superheat}

The meniscus profiles for different levels of superheat from $5 \mathrm{~K}$ to $0.01 \mathrm{~K}$ are compared in Fig. 6. It is seen that the apparent contact angle grows with superheat. The decrease in disjoining pressure causes liquid to be pumped into the thin film. When the superheat is increased, evaporation is strengthened and more liquid needs to be pumped into the thin film, decreasing the disjoining pressure faster and finally resulting in a larger apparent contact angle, which is consistent with previous studies [6-9]. Also as seen in Table 2(b), the contribution of the thin film to the overall heat transfer is increased.

In Section 2.2, Eq. (7) [17] and Eq. (10) [4] were compared, and it was found that for larger superheat (> $5 \mathrm{~K}$ ), the simplified Eq. (10) underestimates the evaporation mass flux. The impact of the two equations on the thin film calculation is shown in Fig. 7. Two different superheat levels are considered, $5 \mathrm{~K}$ and $20 \mathrm{~K}$. It is seen that for superheats of up to $5 \mathrm{~K}$, predictions from the two equations still agree well with each other. For very high values of superheat, such as those which may occur at the bottom of a bubble during nucleate boiling, Eq. (10) underestimates the heat transfer and results in a flatter thickness profile.

Fig. 7 also investigates the influence of approximations made in the evaluation of the coefficients $a$ and $b$ in Eq. (10). The interfacial temperature $T_{l v}$ in the coefficients $a$ and $b$ has been commonly replaced by $T_{w}$ [28] for convenience in the literature. This is appropriate when the wall superheat is small, so that $T_{l v} \approx T_{w}$. For high superheat, however, it is more appropriate to use $T_{l v} \approx T_{v}$, as seen in the figure. 


\subsection{Suppression of Interface Mass Transport due to Capillary Pressure}

While the suppression effect of disjoining pressure on thin film evaporation has been widely discussed [4-6,9-10], a similar discussion of the effect of capillary pressure has seldom been reported. The interfacial evaporation heat transfer coefficient $h_{l v}$ is plotted in Fig. 8 for wall superheats of $0.1 \mathrm{~K}$ and $1 \mathrm{~K}$. It is clear that $h_{l v}$ is suppressed in the beginning due to the disjoining pressure as has been extensively discussed in the literature [4-10]. After a peak at $x \approx 400 \mathrm{~nm}, h_{l v}$ is seen to decrease again, this time because of the suppression due to capillary pressure. If the suppression due to capillary pressure were ignored, $h_{l v}$ would follow the dashed line in the figure and approach a higher constant value of $1.04 \times 10^{6} \mathrm{~W} / \mathrm{m}^{2} \mathrm{~K}$, which is consistent with published values of $h_{l v}$ for situations that do not encounter suppression effects due to capillary pressure [17].

The drop in $h_{l v}$ is more significant for lower $T_{l v}$. If the wall superheat is increased from $0.1 \mathrm{~K} \mathrm{to} 1 \mathrm{~K}$, the interface temperature is greater, and the restraining effect becomes less significant, as shown in the figure. This trend can also be deduced from Eq. (10)by using definition of $h_{l v}$ :

$$
h_{l v}=h_{f g}\left[a-b\left(p_{d}+p_{c}\right) \frac{1}{\left(T_{l v}-T_{v}\right)}\right]
$$

$h_{\mathrm{fg}}$ is the latent heat of evaporation. It is seen that a smaller $\left(T_{l v}-T_{v}\right)$ amplifies the second term in the brackets, which represents the suppression of $h_{l v}$. When $\left(T_{l v}-T_{v}\right)$ is small enough, based on this equation, $h_{l v}$ can even take a negative value.

It may be noted from the figure that even though the capillary pressure approaches a constant value beyond $x \approx 400 \mathrm{~nm}, h_{l v}$ continues to decrease because of the continuous drop in interface temperature $T_{l v}$. As $T_{l v}$ decreases with increasing film thickness, the restraining effect of $P_{c}$ increases.

The restraining effect of capillary pressure is also seen to be more significant for smaller channels as shown in Fig. 9, since the intrinsic meniscus has greater curvature and capillary pressure is stronger in the smaller channels.

Finally, a higher dispersion constant $A$ is known to result in a longer thin-film region and to promote heat transfer [4-10]. A higher capillary pressure (due to a higher value of surface tension) also flattens the film profile. The flattened profile shown in Fig. 10 has smaller thickness and the heat transfer is expected to be enhanced. However the heat transfer is not always enhanced as shown in Fig. 10 because higher capillarity also causes greater suppression of evaporation. In [9], the effect of fluid polarity was found to elongate the thin-film region and cause stronger suppression, similar to the effects of capillary pressure discussed here. 


\section{MICRO REGION HEAT TRANSFER}

In this work, the micro region of a meniscus is defined as the region in which the film thickness is less than $1 \mu \mathrm{m}$. The region with film thickness greater than $1 \mu \mathrm{m}$ is referred to as the macro region. Table 3(a) and (b)show the length and heat transfer of the micro region for different channel sizes and superheats. The length of the micro region is seen to be more than ten times that of the thin-film region, which is typically about $100 \mathrm{~nm}$ in length (Table 2(a)).

It was previously seen from Table 2(a) that the thin-film heat transfer $q_{t}$ is not very significant for large microchannels. For example, for $R^{*}=61 \mu \mathrm{m}, q_{t}$ is only $8 \%$ of the overall heat transfer. However, Fig. 11 and Table 3(b) show that the micro region is responsible for $60 \%$ of the overall heat transfer in the same channel. The results under different superheats and channel sizes are listed in Table 3(a) and (b). In Stephan and Busse's study of an ammonia meniscus in a groove of $1 \mathrm{~mm}$ height and $1 \mathrm{~mm}$ width [12], 45\% of the overall heat transfer was found to be dissipated from the micro region, consistent with the calculations in the present study. It is concluded that the micro region is, in general, much more important to the overall heat transfer than is the thin film for the range of parameters considered here.

It is also found that the temperature drop along the interface mainly occurs within micro region rather than in the macro region. As shown in Fig. 12, $T_{l v}$ drops sharply in the micro region (of $3.94 \mu \mathrm{m}$ length) from 344 $\mathrm{K}$ to $343.1 \mathrm{~K}$, accounting for $90 \%$ of the total drop. In the macro region, the interfacial temperature is close to the saturation temperature, and can drive relatively little evaporation. In the thin-film region (of $160 \mathrm{~nm}$ length), the drop is from $344 \mathrm{~K}$ to $343.8 \mathrm{~K}$, which is about $20 \%$ of the total drop.

\section{CONCLUSIONS}

The thin-film region of an evaporating meniscus is investigated through an augmented Young-Laplace model. The boundary conditions for the film profile are discussed in detail. The primary conclusions of the study are summarized below.

1. The thin-film region of the extended meniscus is delineated. The influence of channel radius on heat transfer rate is found to be most pronounced in the intrinsic meniscus and not in the thin-film region. The contribution of the thin-film region to the overall heat transfer is inversely proportional to the channel size and wall superheat. In a microchannel with a superheat of greater than $1 \mathrm{~K}$, the thin film is shown to contribute less than $20 \%$ of the total heat transfer from the liquid film.

2. The micro region is seen to be the major contributor to the overall heat transfer from the extended meniscus. It consists of the thin film region and a part of the intrinsic meniscus. More than $50 \%$ of the overall heat transfer and $90 \%$ of the interfacial temperature drop occur in the micro region for the conditions considered here. 
3. The original mass transport expression without approximations is employed to study a wide superheat range and is compared to the simplified expression that has been widely used in the literature [4]. The simplified expression is found to significantly underestimate the interfacial evaporation heat transfer coefficient for superheats above $5 \mathrm{~K}$, and induces significant deviations in the computed thin film profile for superheats above $20 \mathrm{~K}$.

4. Capillary pressure plays an important role in determining the film profile throughout the extended meniscus. Its effect on suppressing evaporation is significant for small channels and low superheats.

\section{Acknowledgement}

The authors acknowledge financial support for this work from members of the Cooling Technologies Research Center (www.ecn.purdue.edu/CTRC), a National Science Foundation Industry/University Cooperative Research Center at Purdue University.

\section{REFERENCES}

[1] B.V. Deryagin, S.V. Nerpin, N.V. Churayev, Effect of film heat transfer upon evaporation of liquids from capillaries, Bull. R. I. L. E. M. 29 (1965) 93-98.

[2] B.V. Deryagin, Modern state of the investigation of long-range surface forces, Langmuir 3 (5) (1987) 601606.

[3] Potash, M., Jr., P. C. Wayner, Jr., Evaporation from a two-dimensional extended meniscus, International Journal of Heat and Mass Transfer 15 (1972) 1851-1863.

[4] P.C. Wayner, Jr., Y.K. Kao, L.V. LaCroix, The interline heat transfer coefficient of an evaporating wetting film, Internal Journal of Heat and Mass Transfer 19 (1976) 487-492.

[5] J. A. Schonberg, P. C. Wayner, Jr., Analytical solution for the integral contact line evaporation heat sink, AIAA/ASME $5^{\text {th }}$ Joint Thermophysics and Heat Transfer Conference, Seattle, AIAA-1990-1787, 1990

[6] K.P. Hallinan, H.C. Chebaro, S.J. Kim, W.S. Chang, Evaporation from an extended meniscus for nonisothermal interfacial conditions, Journal of Thermophysics and Heat Transfer 8 (1994) 709-716.

[7] S. DasGupta, J.A. Schonberg, P.C. Wayner, Jr., Investigation of an evaporating extended meniscus based on the augmented Young-Laplace Equation, Journal of Heat and Mass Transfer 115 (1993) 201-208.

[8] K. Park, K. Noh, K. Lee, Transport phenomena in the thin-film region of a micro-channel, International Journal of Heat and Mass Transfer 46 (2003) 2381-2388.

[9] S.K. Wee, Microscale observables for heat and mass transport, Ph.D. Thesis, Texas A\&M University, 2004

[10] S. Wee, K.D. Kihm, D.M. Pratt, and J.S. Allen, Microscale heat and mass transport of evaporating thin film of binary mixture, Journal of Thermophysics and Heat Transfer 20 (2006) 320-327.

[11] J.B. Freund, The atomic detail of an evaporating meniscus, Physics of Fluids 17 (2005) 022104

[12] P.C. Stephan, C.A. Busse, Analysis of the heat transfer coefficient of grooved heat pipe evaporator walls, International Journal of Heat and Mass Transfer 35 (1992) 383-391.

[13] X. Xu, V.P. Carey, Film evaporation from a micro-grooved surface - An approximate heat transfer model and its comparison with experimental data, Journal of Thermophysics and Heat Transfer 4 (1990) 512-520.

[14] H.B. Ma, G.P. Peterson, Temperature variation and heat transfer in triangular grooves with an evaporating film, Journal of Thermophysics and Heat Transfer 11 (1997) 90-97.

[15] S.J.S. Morris, The evaporating meniscus in a channel, Journal of Fluid Mechanics 494 (2003) 297-317.

[16] C. Chakraborty, S.K. Som, Heat transfer in an evaporating thin liquid film moving slowly along the walls of an inclined microchannel, International Journal of Heat and Mass Transfer 48 (2005) 2801-2805. 
[17] R.W. Schrage, A theoretical study of interface mass transfer, Columbia University Press, New York, 1953. [18] B.V. Derjaguin, Z.M. Zorin, Optical study of the adsorption and surface condensation of vapours in the vicinity of saturation on smooth surface, Proc. $2^{\text {nd }}$ International Conference of Surface Activity, 2, 1957 , pp.145-152.

[19] V.P. Carey, Liquid-vapor phase-change phenomena, New York: Hemisphere Publishing House, 1992. [20] D.J.E. Harvie, D.F. Fletcher, A simple kinetic theory treatment of volatile liquid-gas interfaces, Journal of Heat Transfer, 123 (2001) 487-491.

[21] A. Faghri, Heat pipe science and technology, Taylor \& Francis, Washington, DC, 1995.

[22] B. Paul, Complication of evaporation coefficients, American Rocket Society. Journal 32 (1962) 13211328.

[23] J.A. Schonberg, S. DasGupta, P.C. Wayner, Jr., An augmented Young-Laplace Model of an evaporation meniscus in a microchannel with high heat flux, Experimental Thermal and Fluid Science 10 (1995) 163-170 [24] J.G. Truong, P.C. Wayner, Jr., Effect of capillary and van der Waals dispersion force on the equilibrium profile of a wetting fluid: theory and experiment, Journal of Chemical Physics 87 (1987) 4180-4188

[25] J. R. Dormand, P. J. Prince, A family of embedded Runge-Kutta formulae, Journal of Computational and Applied Mathematics 6 (1980) 19-26.

[26] L.W. Swanson, G.C. Herdt, Model of the evaporating meniscus in a capillary tube, Journal of Heat transfer 114 (1992) 434-441.

[27] D. Welter, The effect of evaporation on the dynamic capillary pressure in heat pipes, Master's Thesis, University of Dayton, Ohio, 1991.

[28] R. Marek, J. Straub, Analysis of the evaporation coefficient and the condensation coefficient of water, International Journal of Heat and Mass Transfer 44 (2001) 39-53. 


\section{LIST OF TABLES}

Table 1. Properties of evaporating liquid [5] and operating conditions.

Table 2 Thin film region for (a) different channel sizes (superheat $1 \mathrm{~K}$ )

Table 3. Micro region for (a) different channel sizes (superheat $1 \mathrm{~K})$; and (b) different superheats $\left(R^{*}=61\right.$ $\mu \mathrm{m})$

\section{LIST OF FIGURES}

Fig. 1. Schematic diagram and coordinate system for an evaporating thin film in a channel.

Fig. 2. Comparison of mass fluxes obtained using Eq. (7) from Schrage [17] and Eq. (10) from Wayner et al. [4]. The calculations are performed for octane with properties as in Table 1. A value of (a) $104 \mathrm{~Pa}$, and (b) $0 \mathrm{~Pa}$ is assumed for suppression pressure $(\mathrm{Pd}+P c)$.

Fig. 3. Influence of initial thin film thickness $\delta(0)$ on the cumulative heat transfer from the thin-film region as well as on the capillary pressure (intrinsic meniscus radius $R^{*}=2500 \mathrm{~nm}$ ).

Fig. 4. Variation of the different pressure components along the length of the meniscus (superheat $1 \mathrm{~K}$ ): $R^{*}=2500 \mathrm{~nm}$, and $(b) R^{*}=200 \mathrm{~nm}$.

Fig. 5. Thin film with different channel sizes $\left(\mathrm{R}^{*}=200,400,2500\right.$, and 6.1×104 nm): (a) film thickness, and (b) cumulative $q$.

Fig. 6. Effect of superheat on the film thickness profile $\left(R^{*}=2500 \mathrm{~nm}\right)$.

Fig. 7. Comparison between thin film predictions from Eq. (7) [17] and Eq. (10) [4] for different values of superheat $\left(\mathrm{R}^{*}=2500 \mathrm{~nm}\right)$ : (a) thickness profile, and (b) cumulative $\mathrm{q}$.

Fig. 8. Interface heat transfer coefficient along the meniscus. Heat transfer is suppressed by the disjoining pressure to the left of the peak and by capillary pressure to the right. Lower superheat results in stronger suppression $\left(R^{*}=2500 \mathrm{~nm}\right)$. 
Fig. 9. Capillary suppression of cumulative heat transfer for different channel sizes $\left(\mathrm{R}^{*}=110\right.$ and $\left.400 \mathrm{~nm}\right)$; the smaller channel size results in greater suppression.

Fig. 10. Influence of increasing surface tension on cumulative heat transfer and film thickness $\left(\mathrm{R}^{*}=2500\right.$ $\mathrm{nm})$.

Fig. 11. Cumulative heat transfer $q$ increase with thickness: (a) overall variation, and (b) detail near origin. The solid line divides the micro and macro regions, while the dashed line divides the thin film region and the intrinsic meniscus (superheat of $1 \mathrm{~K}, R^{*}=61 \mu \mathrm{m}$ ).

Fig. 12. Decrease in interfacial temperature along the liquid film; $90 \%$ of the temperature drop occurs within the micro region. 
Table 1. Properties of evaporating liquid [5] and operating conditions.

\begin{tabular}{|c|c|}
\hline Liquid & Octane \\
\hline$A(\mathrm{~J})$ & $-3.18 \times 10^{-21}$ \\
\hline$P_{v}(\mathrm{~Pa})$ & $1.5828 \times 10^{4}$ \\
\hline$\rho_{l}\left(\mathrm{~kg} / \mathrm{m}^{3}\right)$ & 661.2 \\
\hline$k_{l}(\mathrm{~W} / \mathrm{mK})$ & 0.11 \\
\hline$h_{f g}(\mathrm{~kJ} / \mathrm{kg})$ & 339.8 \\
\hline$T_{w}(\mathrm{~K})$ & 344 \\
\hline$T_{v}(\mathrm{~K})$ & 343 \\
\hline$\hat{\sigma}$ & 1 \\
\hline
\end{tabular}


Table 2 Thin film region for (a) different channel sizes (superheat $1 \mathrm{~K})$, and (b) different superheats $\left(R^{*}=\right.$ $2500 \mathrm{~nm}$ ).

(a)

\begin{tabular}{|c|c|c|c|c|}
\hline$R^{*}(\mathrm{~nm})$ & 200 & 2500 & $6.1 \times 10^{4}$ & $2.1 \times 10^{5}$ \\
\hline Thin film length (nm) & 95 & 154 & 160 & 160 \\
\hline $\begin{array}{c}\text { Thickness at the end of } \\
\text { thin film }(\mathrm{nm})\end{array}$ & 21 & 21 & 21 & 21 \\
\hline $\begin{array}{c}\text { Thin film heat transfer } \\
q_{t}(\mathrm{~W} / \mathrm{m})\end{array}$ & 0.08 & 0.139 & 0.141 & 0.141 \\
\hline $\begin{array}{c}\text { Percentage contribution } \\
\text { to net heat transfer rate }\end{array}$ & $53 \%$ & $20 \%$ & $8 \%$ & $5 \%$ \\
\hline
\end{tabular}

(b)

\begin{tabular}{|c|c|c|c|c|c|c|}
\hline Superheat (K) & 0.01 & 0.04 & 0.1 & 1 & 5 & 20 \\
\hline Thin film length (nm) & 1096 & 666 & 585 & 154 & 63 & 28 \\
\hline $\begin{array}{c}\text { Thickness at the end of } \\
\text { thin film (nm) }\end{array}$ & 99 & 74 & 45 & 21 & 12 & 7 \\
\hline $\begin{array}{c}\text { Thin film heat transfer } \\
q_{t}(\mathrm{~W} / \mathrm{m})\end{array}$ & $9.5 \times 10^{-5}$ & $1.6 \times 10^{-2}$ & 0.035 & 0.139 & 0.32 & 0.68 \\
\hline $\begin{array}{c}\text { Percentage contribution } \\
\text { to net heat transfer rate }\end{array}$ & $69 \%$ & $54 \%$ & $43 \%$ & $20 \%$ & $12 \%$ & $9 \%$ \\
\hline
\end{tabular}


Table 3. Micro region for (a) different channel sizes (superheat $1 \mathrm{~K})$, and (b) different superheats $\left(R^{*}=61\right.$ $\mu \mathrm{m})$

(a)

\begin{tabular}{|c|c|c|c|}
\hline$R^{*}(\mathrm{~nm})$ & 2500 & $6.1 \times 10^{4}$ & $2.1 \times 10^{5}$ \\
\hline Micro region length $(\mathrm{nm})$ & 1653 & 3945 & 4275 \\
\hline$q_{m}(\mathrm{~W} / \mathrm{m})$ & 0.64 & 1.14 & 1.2 \\
\hline $\begin{array}{c}\text { Percentage contribution } \\
\text { to net heat transfer rate }\end{array}$ & $97 \%$ & $60 \%$ & $50 \%$ \\
\hline
\end{tabular}

(b)

\begin{tabular}{|c|c|c|}
\hline Superheat $(\mathrm{K})$ & 1 & 5 \\
\hline Micro region length $(\mathrm{nm})$ & 3945 & 2593 \\
\hline$q_{m}(\mathrm{~W} / \mathrm{m})$ & 1.14 & 3.70 \\
\hline $\begin{array}{c}\text { Percentage contribution } \\
\text { to net heat transfer rate }\end{array}$ & $60 \%$ & $56 \%$ \\
\hline
\end{tabular}




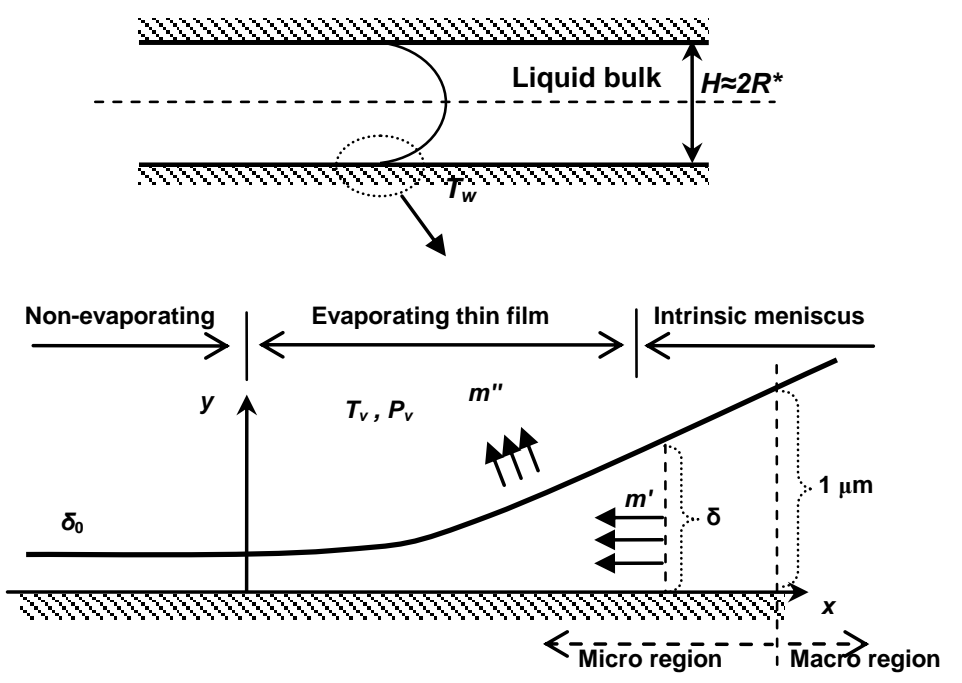

Fig. 1. Schematic diagram and coordinate system for an evaporating thin film in a channel. 


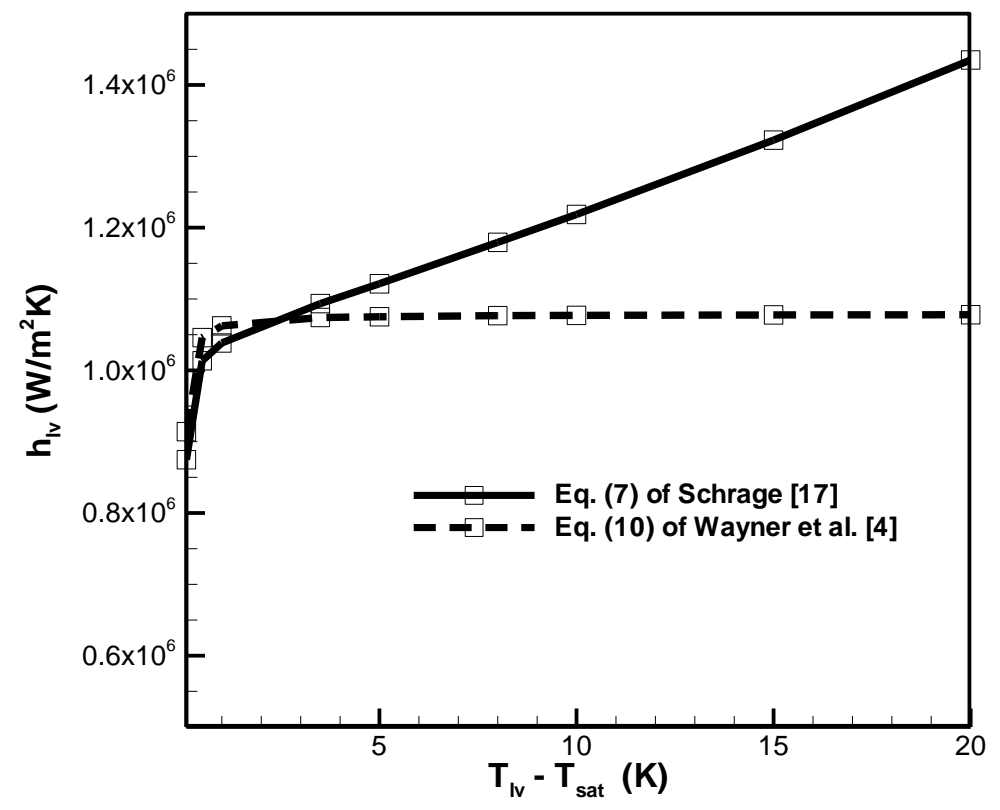

(a)

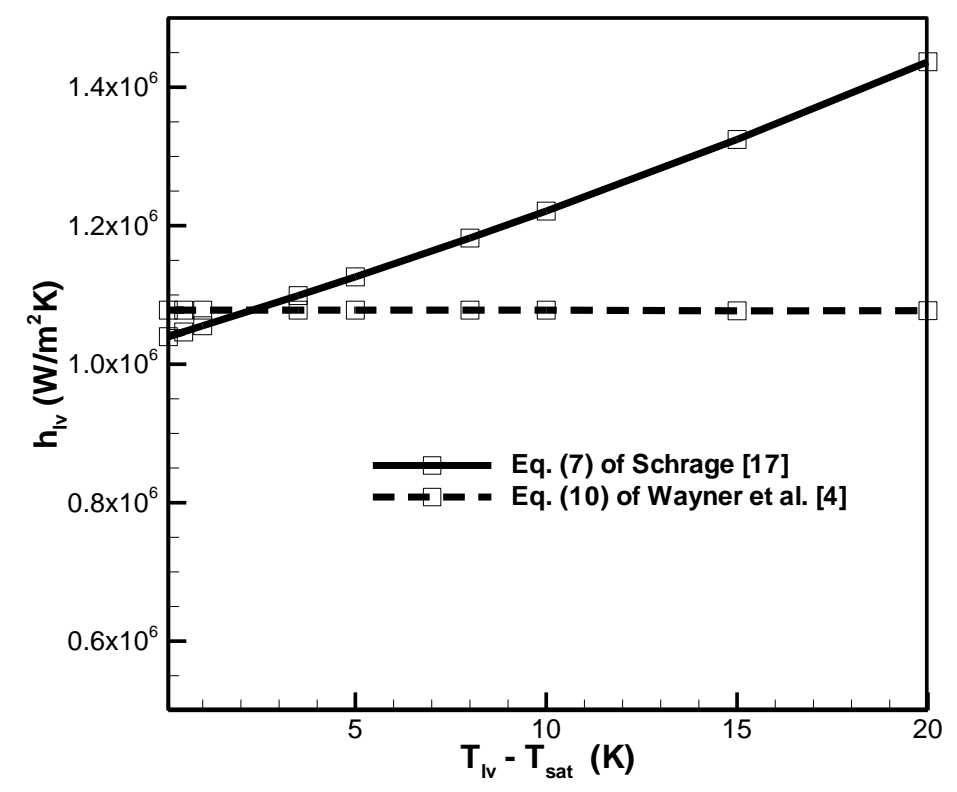

(b)

Fig. 2. Comparison of mass fluxes obtained using Eq. (7) from Schrage [17] and Eq. (10) from Wayner et al. [4]. The calculations are performed for octane with properties as in Table 1 . A value of (a) $10^{4} \mathrm{~Pa}$, and (b) $0 \mathrm{~Pa}$ is assumed for suppression pressure $\left(P_{d}+P_{c}\right)$. 


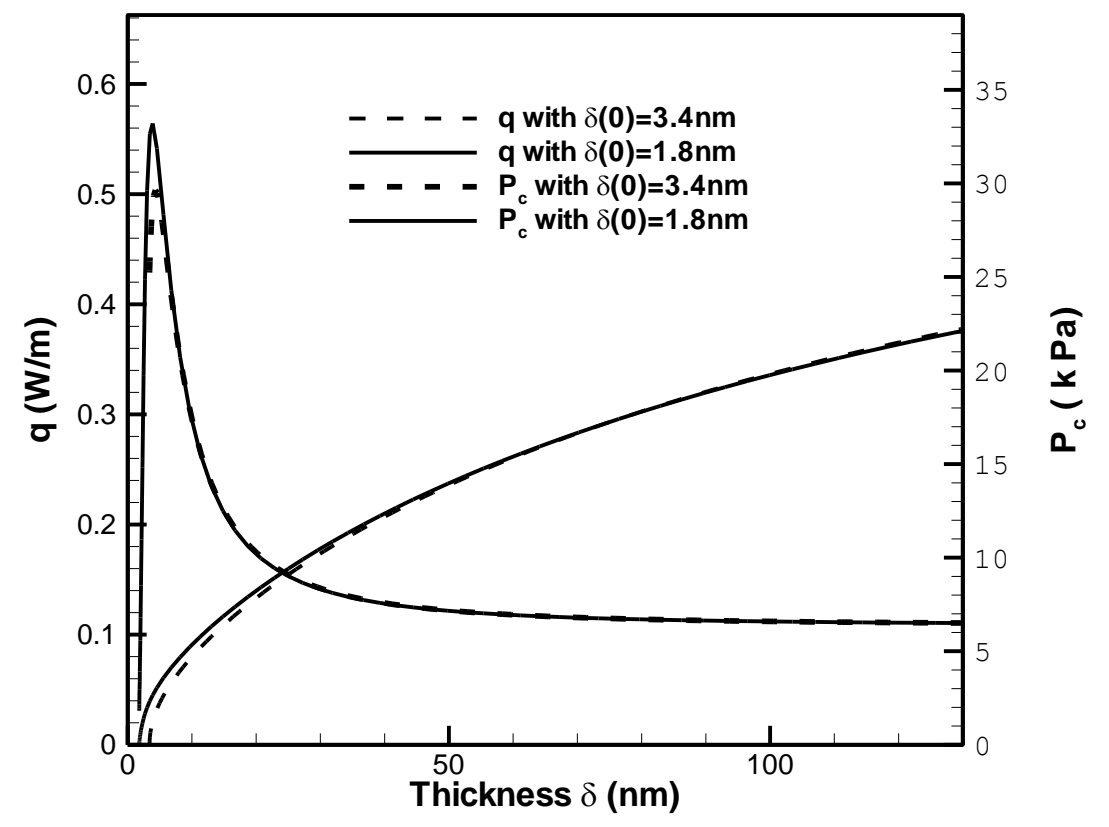

Fig. 3. Influence of initial thin film thickness $\delta(0)$ on the cumulative heat transfer from the thin-film region as well as on the capillary pressure (intrinsic meniscus radius $R^{*}=2500 \mathrm{~nm}$ ). 


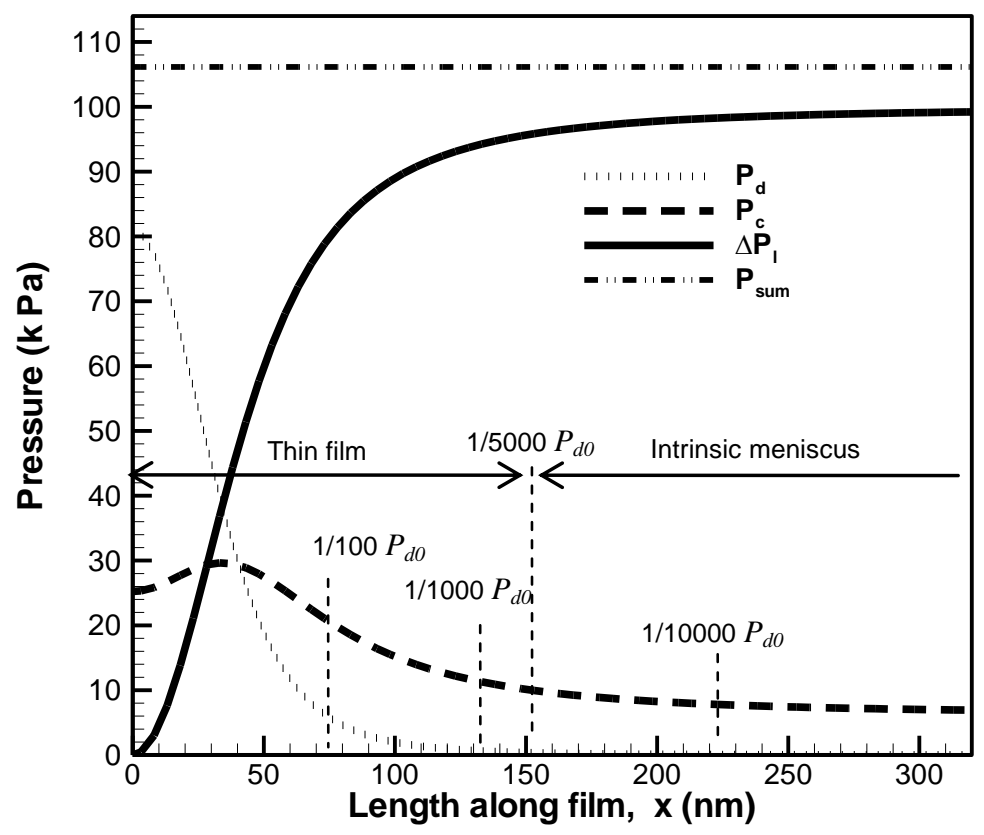

(a)

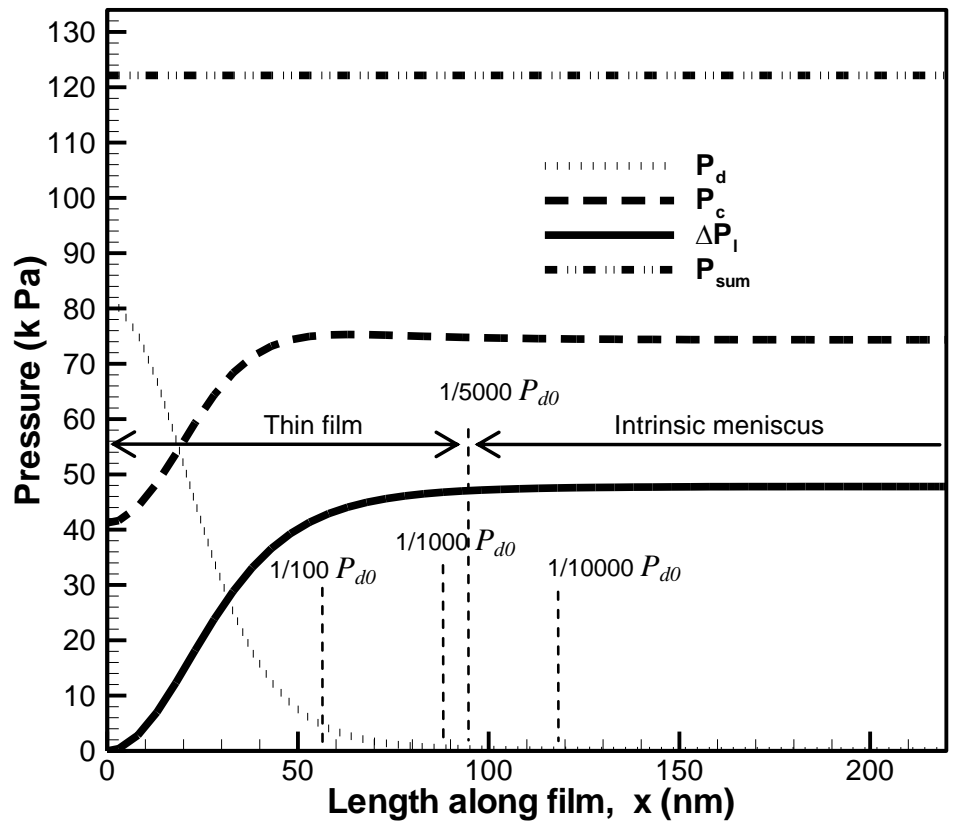

(b)

Fig. 4. Variation of the different pressure components along the length of the meniscus (superheat $1 \mathrm{~K}$ ):

$$
R^{*}=2500 \mathrm{~nm} \text {, and (b) } R^{*}=200 \mathrm{~nm} \text {. }
$$




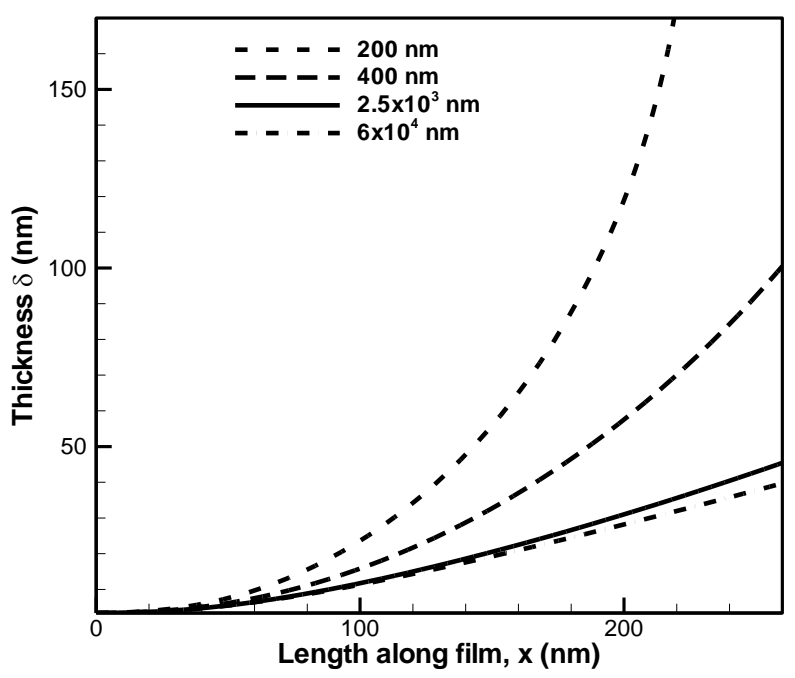

(a)

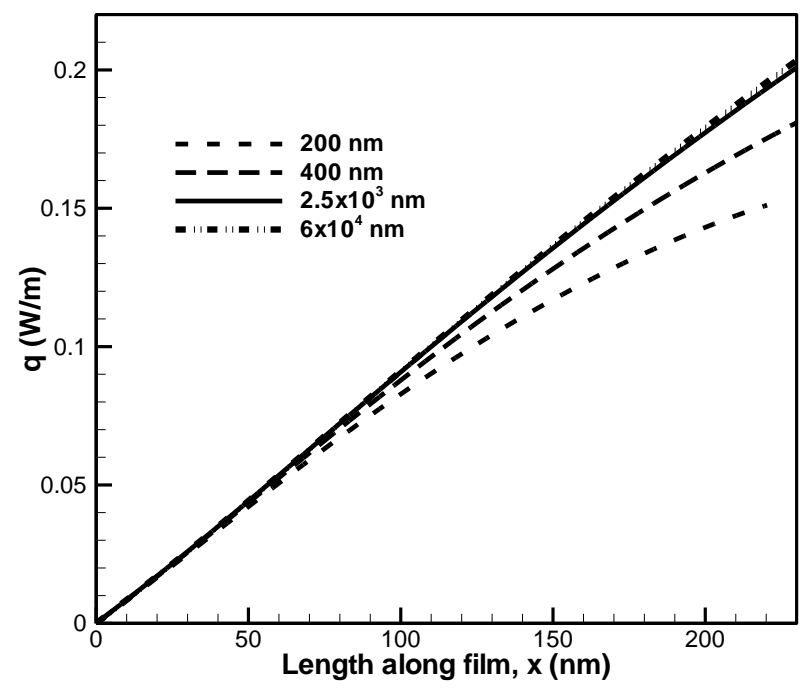

(b)

Fig. 5. Thin film with different channel sizes $\left(R^{*}=200,400,2500\right.$, and $\left.6.1 \times 10^{4} \mathrm{~nm}\right)$ : (a) film thickness, and (b) cumulative $q$. 


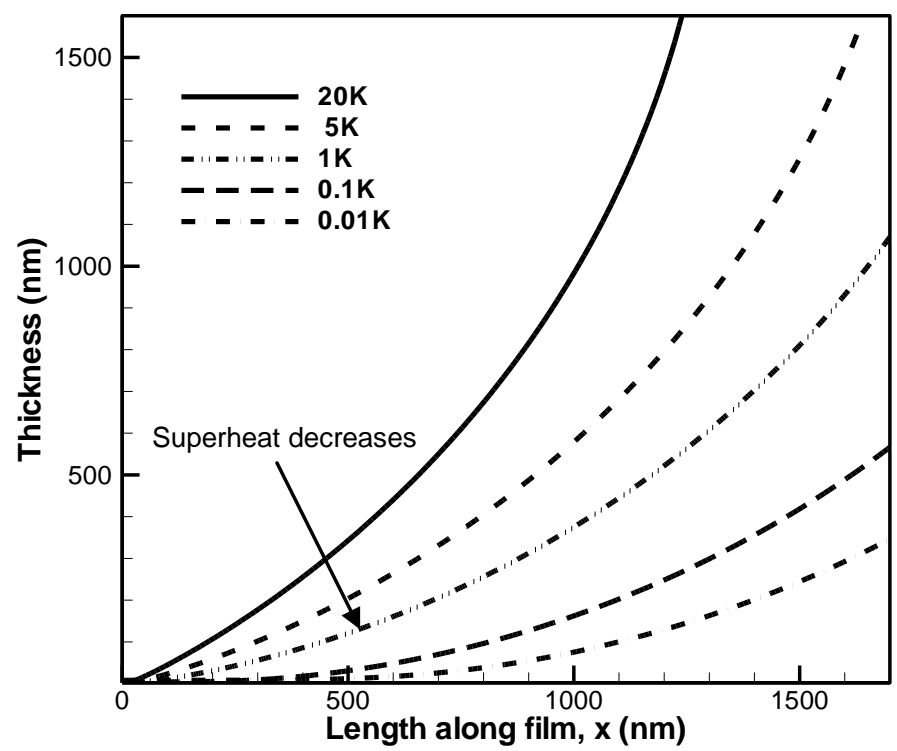

Fig. 6. Effect of superheat on the film thickness profile $\left(R^{*}=2500 \mathrm{~nm}\right)$. 


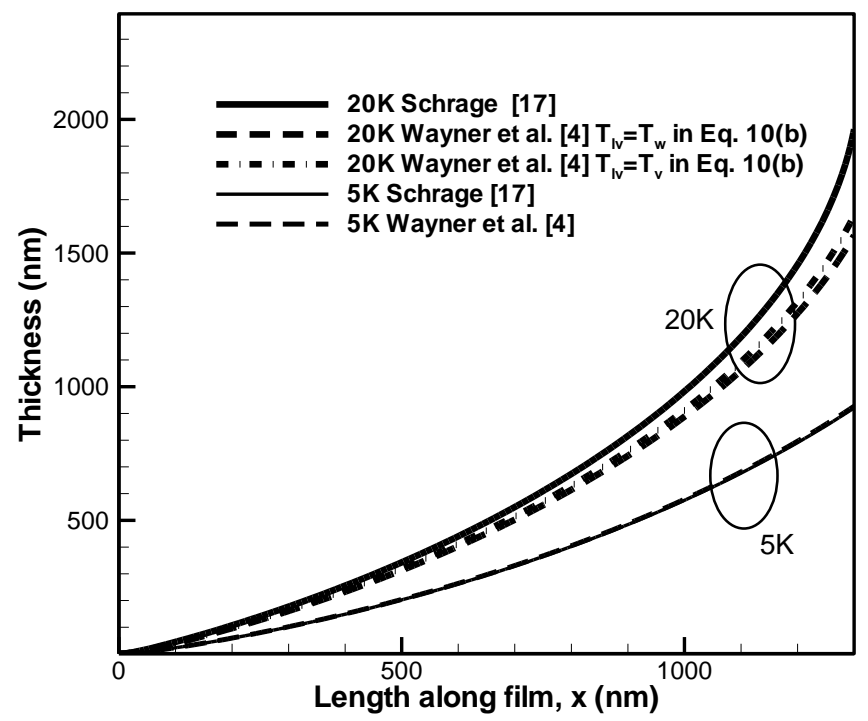

(a)

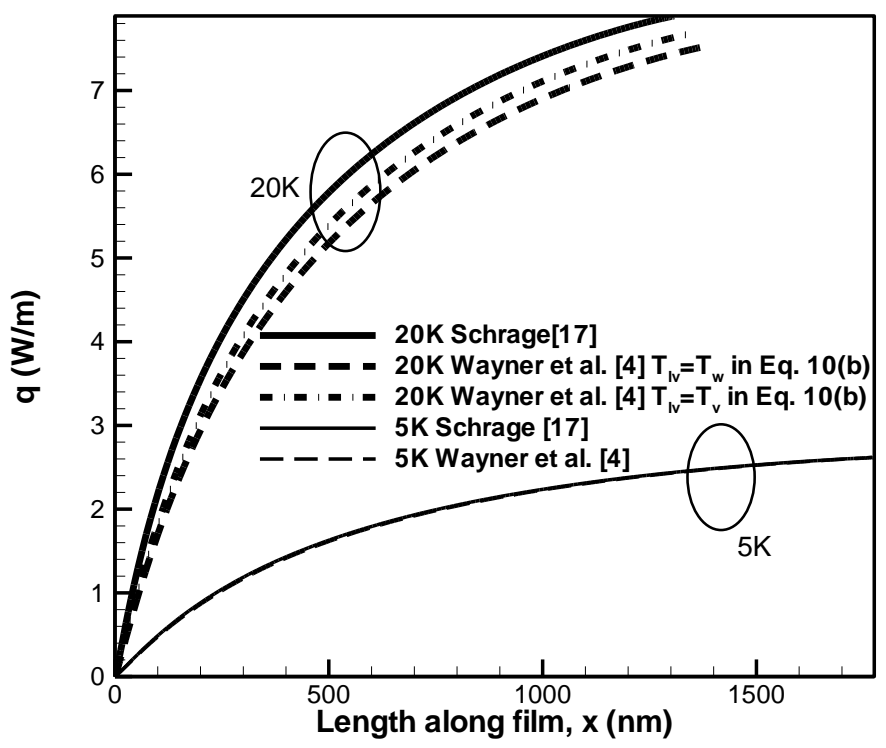

(b)

Fig. 7. Comparison between thin film predictions from Eq. (7) [17] and Eq. (10) [4] for different values of superheat $\left(R^{*}=2500 \mathrm{~nm}\right)$ : (a) thickness profile, and (b) cumulative $q$. 


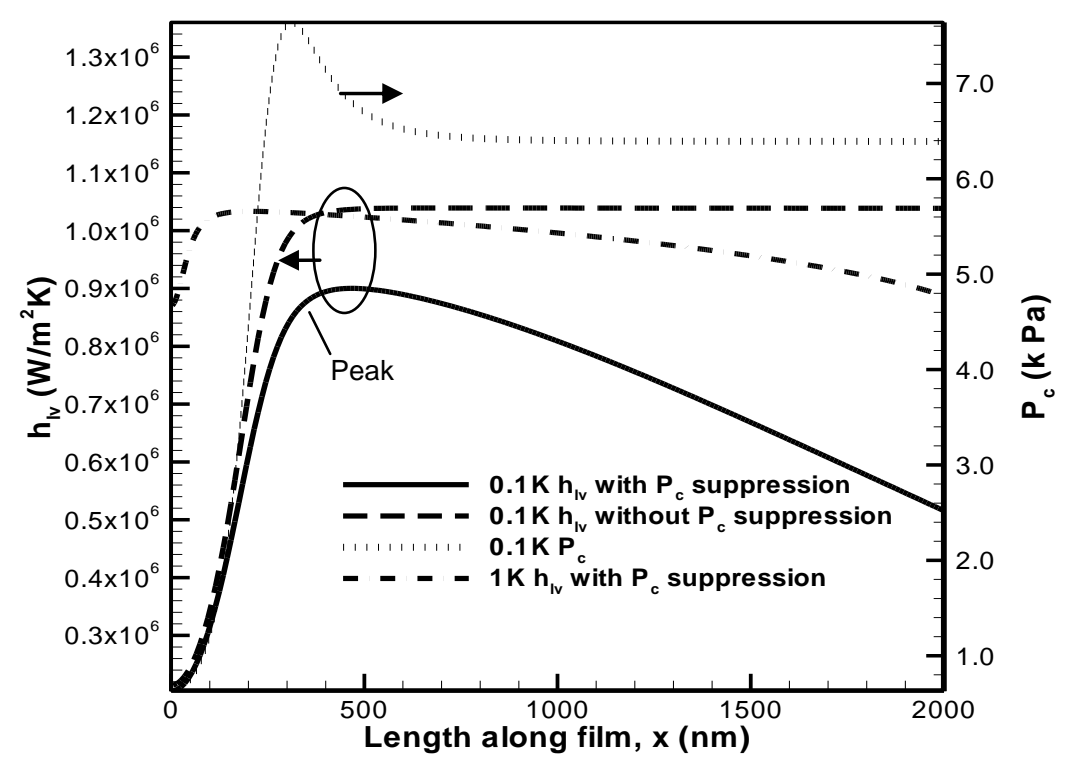

Fig. 8. Interface heat transfer coefficient along the meniscus. Heat transfer is suppressed by the disjoining pressure to the left of the peak and by capillary pressure to the right. Lower superheat results in stronger suppression $\left(R^{*}=2500 \mathrm{~nm}\right)$. 


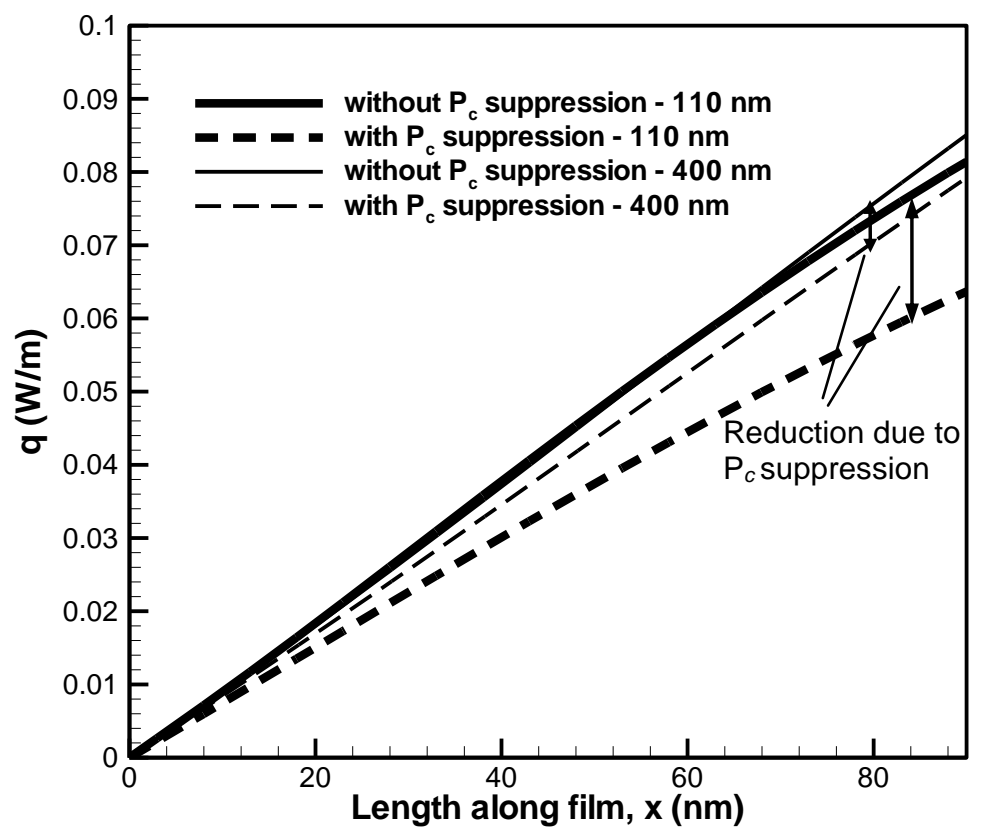

Fig. 9. Capillary suppression of cumulative heat transfer for different channel sizes $\left(R^{*}=110\right.$ and $\left.400 \mathrm{~nm}\right)$; the smaller channel size results in greater suppression. 


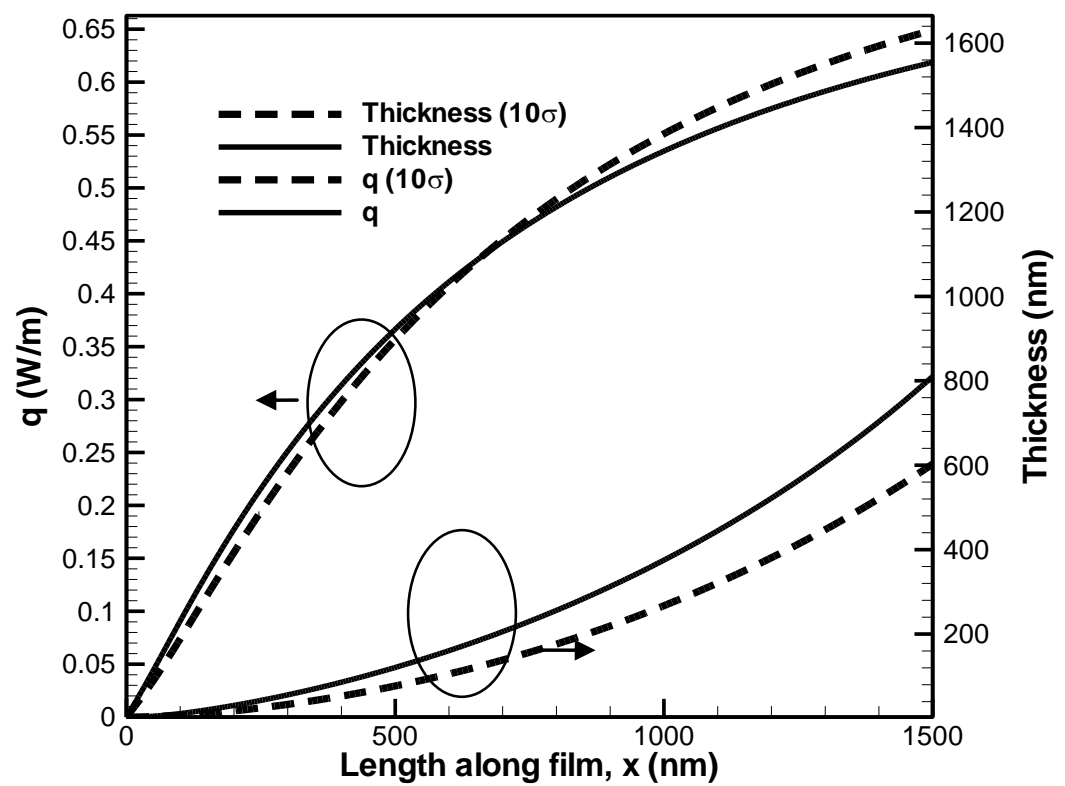

Fig. 10. Influence of increasing surface tension on cumulative heat transfer and film thickness $\left(R^{*}=2500\right.$ $\mathrm{nm})$. 


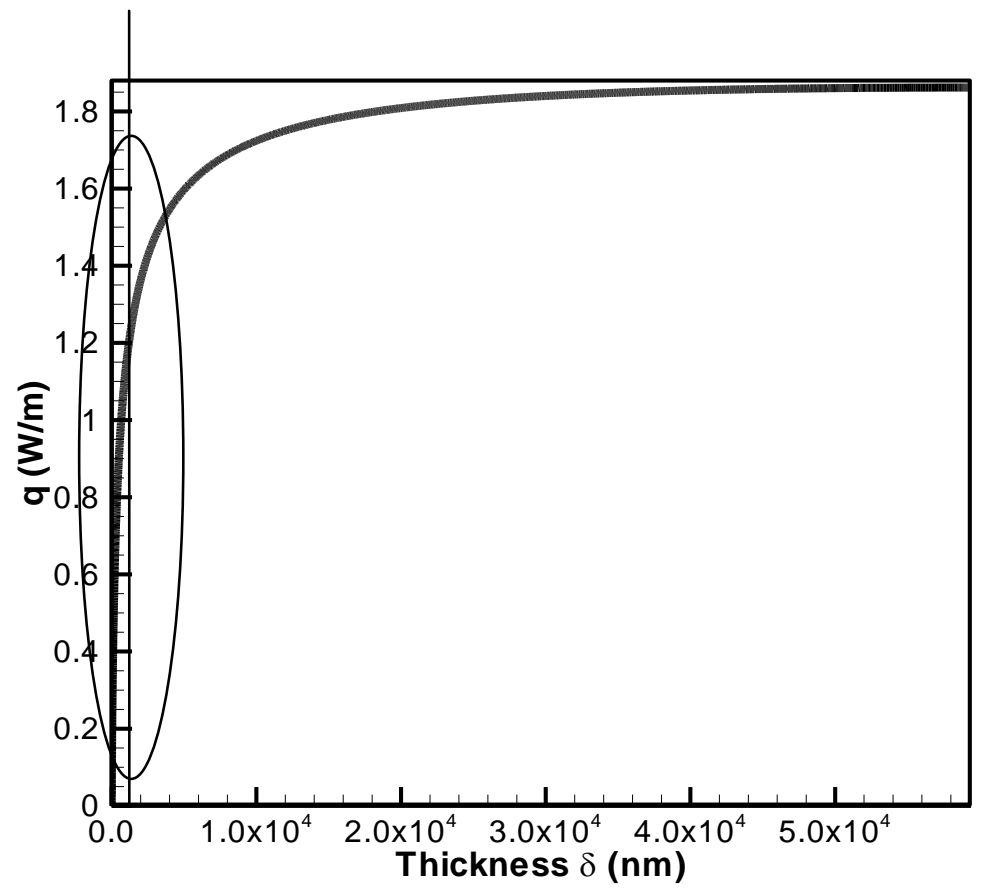

(a)

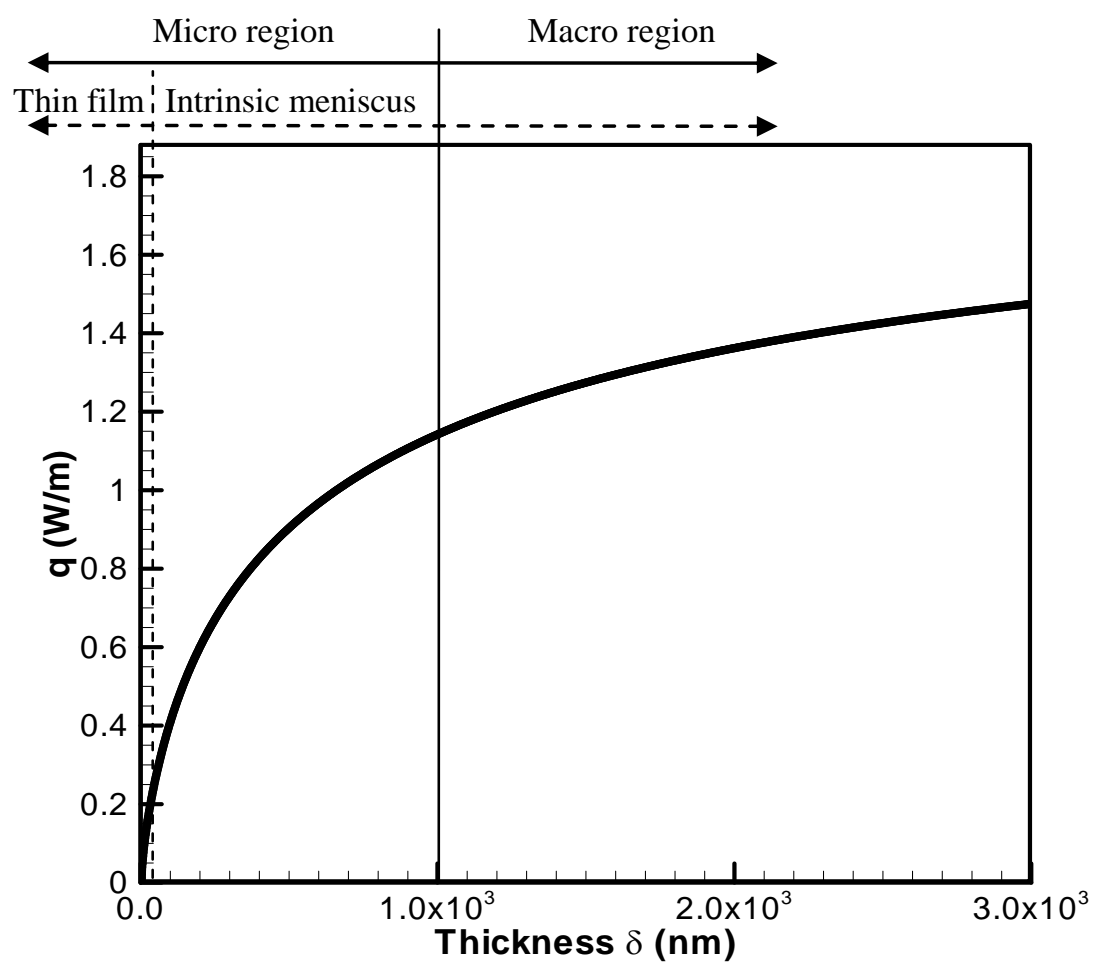

(b)

Fig. 11. Cumulative heat transfer $q$ increase with thickness: (a) overall variation, and (b) detail near origin. The solid line divides the micro and macro regions, while the dashed line divides the thin film region and the intrinsic meniscus (superheat of $1 \mathrm{~K}, R^{\star}=61 \mu \mathrm{m}$ ). 


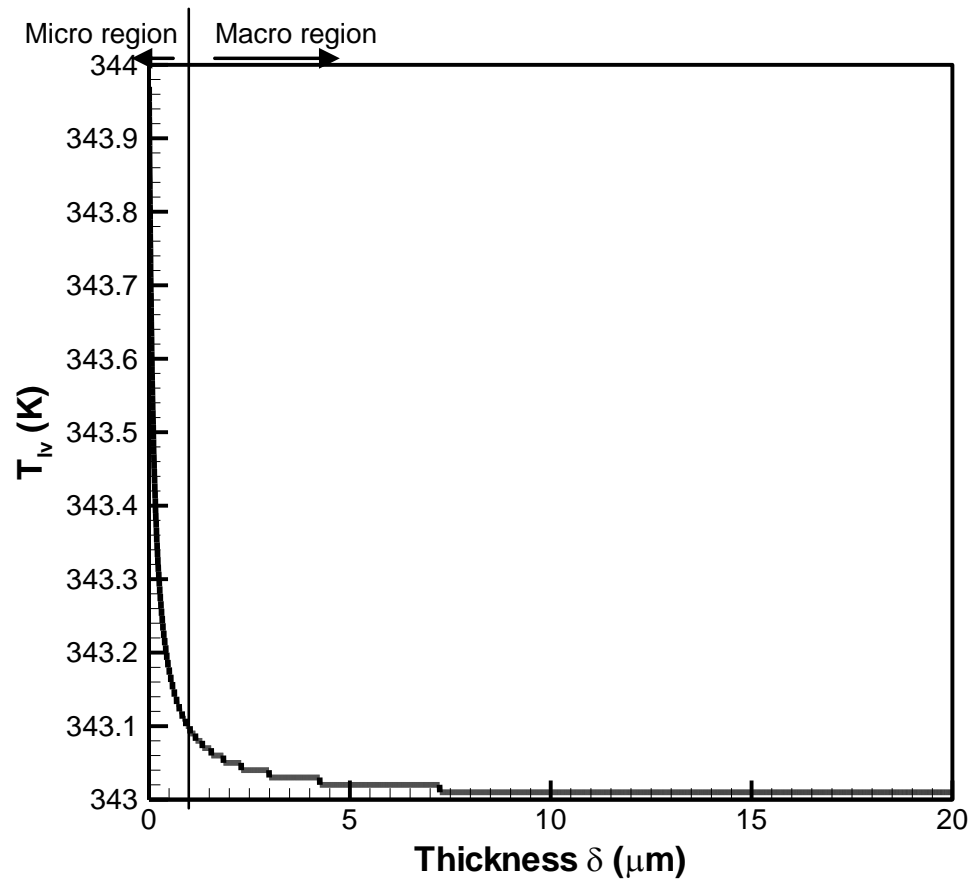

Fig. 12. Decrease in interfacial temperature along the liquid film; $90 \%$ of the temperature drop occurs within the micro region. 